\title{
IOT BASED AUTOMATIC IRRIGATION SYSTEM FOR A SMART CITY
}

\author{
Lalit Mohan Joshi ${ }^{1}$, Rajendra Kumar Bharti ${ }^{2}$, Rajesh Singh ${ }^{3}$ \\ ${ }^{1}$ B.T.K.I.T. Dwarahat, Computer Science and Engineering, India \\ ${ }^{2}$ B.T.K.I.T. Dwarahat, Computer Science and Engineering, India \\ ${ }^{3}$ L.P.U., Electronics and Communication, India \\ ${ }^{1}$ lalitm.joshi09@gmail.com, ${ }^{2}$ rajendramail1980@gmail.com, \\ ${ }^{3}$ srajssssece@gmail.com
}

\begin{abstract}
Irrigation plant appraisement has flown over with various mechanisms, inside of which the primordial irrigation system has several imperfections as per the fact that they don't retrieve water and personage potency. Subsequently, the prolusion of mechanization could relief to overwhelm these drawbacks and assemble a method to retrieve water. It could be completed along with microcontroller of AVR and a single sensor of mold humidity. User could analysis the structure at a reasonable cost for the mechanization of the greenery. Suitable ecological states are essential for finest greenery explosion, advanced plant produce and coherent usage of soil, air and another asset. Designing an uncomplicated, facile to install a circuit which is based on a microcontroller is the main objective as well as in order to enhance them to attain supreme plant distention and proceed to observe and note the expense of soil humidity and planate of compost which is sustainedly amended and moderated.
\end{abstract}

Keywords - Irrigation, Transformer, Atmega microcontroller, A Moisture sensor, Oscillator

\section{INTRODUCTION}

Continuously increasing demand for postulates the prompt furtherance in the technology of meal rations. We are not capable to create total usage of farming assets, in a nation, where the providence is mostly hanged on farming and the climatological states are isotropic such as India. Deficiency of cloudburst \& shortage of ground repertoire water is the primary cause. The maximum part of the land is being involved gradually in the areas of un-irrigated land because of the persistent withdrawal of water from the ground is downsizing the level of water. An unintentional usage of water because of a considerable quantity of wastage water is another important reason. Water is outfitted close to the source region of the greenery as per essential to which an enormous amount of water is rescued is the best consequential benefit has become in the current distill sprinkling system. The agronomist has been using sprinkling approach in India at the existing period over the standard command in which at the usual interludes the agronomists sprinkle the land. 


\subsection{COMPONENTS USED -}

\subsubsection{POWER SUPPLY}

\subsubsection{ATMEGA 16 MICROCONTROLLER}

1.1.3. RELAY

1.1.4. CAPACITOR

1.1.5. RESISTOR

1.1.6. CRYSTAL OSCILLATOR

1.1.7. SOIL MOISTURE SENSOR

1.1.8. DC MOTOR

1.1.9. TRANSISTOR

1.1.10. DIODE

\section{SOIL MOISTURE SENSOR}

In the system of greenery sprinkling, the sensor of soil humidity is a pivotal aspect. For the magnitude of the soil humidity, there are various methods. By the friction affects of the humid soil, here we magnitude the humidity level of it. The humid soil regulates electricity superior in contrast to the drain one as we know passim it. The drain soil's solidity level is better than the dampish one. In our project, a normal soil humid sensor KDQ11 is deployed here. On any occasion, the soil is humid then the sensor provides an output with minor signal and major in the case of drain soil if the sensor is confederate with gauge LM-393. To the controller of A/D pin for cackling the output of analog from this sensor element is sustained.

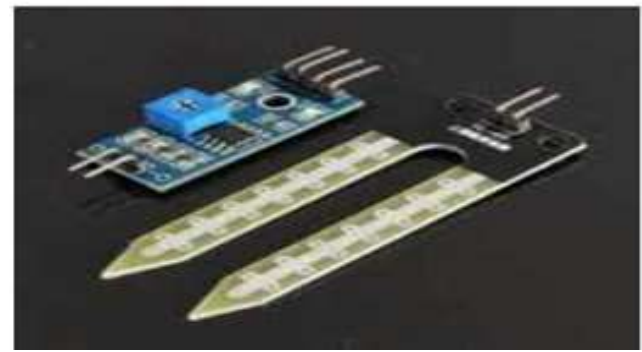

Fig. 1 Soil Moisture Sensor

\subsection{METHOD TO MEASURE THE MOISTURE OF THE SOIL}

For those who could not measure Soil moisture sensor, they can create one on their own; it will be valuable and may be unconventional. For measuring the resistance of soil, interpose 2 cables into drab soil, by spilling a certain amount of water to the soil (moist condition) reiterate this procedure recurrently. Forthwith by utilizing a resistor and the soil, you have to fabricate a voltage resistor network. Based on its state, soil deviates its resistance and performs as a potentiometer. Enumerating the resistor charge you will be expert to utilize that resistance established on it, which you have completed earlier in a dry and wet state. A condition in which switch the pump on, that is influenced by trigger point.

\section{HARDWARE DESCRIPTION}

\subsection{POWER SUPPLY}

Within 5Volt DC Regulator, this circuit is very frequently used. Because of its regulating features, this circuit supports stable 5 Volt DC output here as a regulator, IC7805 is used. Four 1N4001 diodes subsisted with rectifier of bridges and then 
enormous size ac ripples are filtered by a $100 \mathrm{uF}$ capacitor. For implementing the voltage compass from 8 volts to 12 volts of uncontrolled DC voltage to the IC7805 regulator therefore as an input IC pin, 1 is contemplated and on ground Pin, 2 drops then regulated output is inclined by pin 3 . Pin $0.1 \mathrm{uF}$ capacitor is coupled at the output from monitored $\mathrm{DC}$ output to displace narrow extent AC ripples. At last at the output, you will acquire monitored 5 Volt DC at the output.

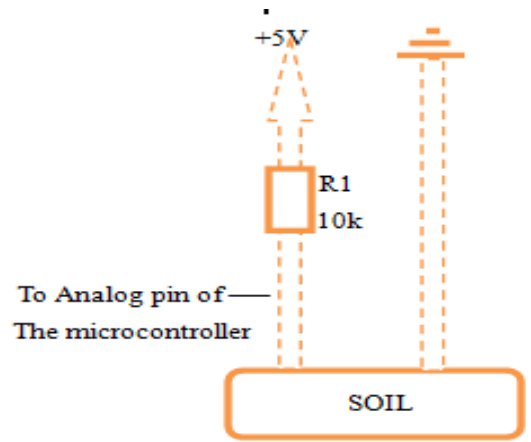

Fig. 2 A power supply in Soil Moisture Sensor

\subsection{ATMEGA16 DESCRIPTION}

From the Atmel's Mega AVR family the ATmega16 is an 8-bit giant pursuance microcontroller. Along with 131 dominant directives, Atmega16 is a 40 pin microcontroller situated on an enriched layout of Reduced Instruction Set Computing (RISC).

It has a 512 Bytes EEPROM, a programmable flash memory of $16 \mathrm{~KB}$ and $1 \mathrm{~KB}$ static RAM. The flash memory's continuation cycle and EEPROM' continuation cycle is 10,000 and 100,000 , respectively. In one machine cycle, almost all of the directives decapitated. On a supreme frequency of $16 \mathrm{MHz}$, it could perform a task. Lines which are distributed into four 8-bit ports denominated as PA, PB, PC, and PD such lines are as 32 I/O (input/output). Different incorporated irrelevant like USART, ADC, Analog Comparator, SPI, JTAG, etc. incorporated with ATmega16. Each and every I/O pin has a substitute effort recount to incorporate incidentals.

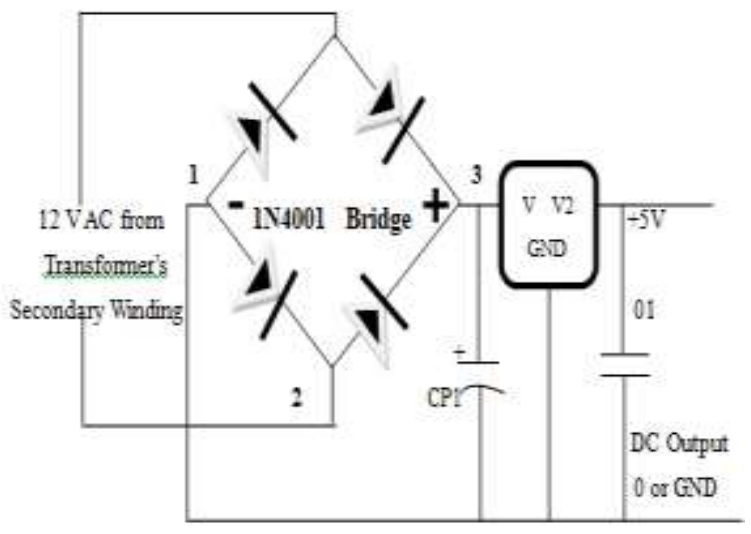

Fig. 3 AT mega 16 


\subsubsection{PIN DESCRIPTION OF AT MEGA 16}

\begin{tabular}{|c|c|c|c|c|c|c|}
\hline (XCKTO & 도 & 1 & 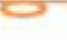 & 40 & a & PAO (ADCO) \\
\hline (T1) PB1 & 대 & 2 & & 39 & a & PA1 (ADC1) \\
\hline (INT2/ANNO) $\mathrm{PB}_{2}$ & 드 & 3 & A & 38 & a & $\operatorname{PAZ}(A D C 2)$ \\
\hline$(O 00 / A N N 1)$ PB3 & 두 & 4 & t & 37 & p & $\mathrm{PA} 3(A \mathrm{DC} B)$ \\
\hline (SS) PB4 & 대 & 5 & $\mathbf{m}$ & 36 & E & $\mathrm{PA} 4(\mathrm{ADC} 4)$ \\
\hline (MOSI) PBS & 더 & 6 & e & 35 & a & $\operatorname{PAS}(A D C 5)$ \\
\hline (MISO) PBE & 뎌 & 7 & $\mathrm{~g}$ & 34 & a & PAG (ADCG) \\
\hline$(\mathrm{SCK}) \mathrm{PB} 7$ & d & 8 & a & 33 & E & PAZ(ADCZ) \\
\hline RESET & 드 & 9 & 1 & 32 & a & ARef \\
\hline$v_{C \infty}$ & 독 & \multicolumn{3}{|c|}{$10(16 / 32), 31$} & g & GND \\
\hline ChND & 두 & \multicolumn{2}{|l|}{11} & 30 & E & $A V_{C C}$ \\
\hline XIAI 2 & 드 & \multicolumn{2}{|l|}{12} & 29 & p & $\mathrm{PC} 7(\operatorname{TOSC2})$ \\
\hline XIAI 1 & 뎌 & \multicolumn{2}{|l|}{13} & 28 & E & PCo(TOSC1) \\
\hline$\left(R_{X D}\right) P D O$ & 드 & \multicolumn{2}{|l|}{14} & 27 & E & PCS(TDI) \\
\hline (TXD) PD1 & 두 & \multicolumn{2}{|l|}{15} & 26 & 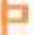 & PCACTDO) \\
\hline (INTO) PD 2 & 도 & \multicolumn{2}{|l|}{16} & 25 & a & $\mathrm{PC} 3$ (TMS) \\
\hline (INT1)PD3 & 도 & \multicolumn{2}{|l|}{17} & 24 & p & РC $2(T C K)$ \\
\hline (OC 1B) PD 4 & 드 & \multicolumn{2}{|l|}{18} & 23 & e & PC1(SDA) \\
\hline (OC1A) PDs & 도 & \multicolumn{2}{|l|}{19} & 22 & Ell & $\mathrm{PCO}(\mathrm{SCL})$ \\
\hline \multirow{2}{*}{\multicolumn{2}{|c|}{ (1CP1) PD6 }} & 20 & & 21 & $p$ & PDZ(OSc2) \\
\hline & & \multicolumn{3}{|c|}{$\begin{array}{c}\text { Pin } \\
\text { Description }\end{array}$} & & \\
\hline
\end{tabular}

Fig. 4 Pin Description of at mega 16

\subsection{STEP DOWN TRANSFORMER}

For converting the low primary voltage to a high secondary voltage, a step-up transformer is used as a device i.e. in which input voltage is stepped up. Contrastingly, to step-down the input voltage a step down transformer is fore owned i.e. the primary voltage is more than secondary voltage. For diminishing electrical voltage, a step-down transformer is designed. Its secondary voltage is minor than the primary voltage.

The voltage which is employed to it is stepped down by this sort of transformer. For occurrence, with a 220v supply in a country, by using a 110v compound a step-down transformer is required. With the help of insulated wire coils (two or more), that is twisted with an essentially mold of iron, by this electrical transformer are produced. The iron core is aggravated by that voltage which is employed to one coil (generally called the input or primary), on the other hand, voltage in the other coil, (normally called the output or secondary) included by same a iron core.

The quantity of voltage variation is determined by the two sets of windings' twist ratio.

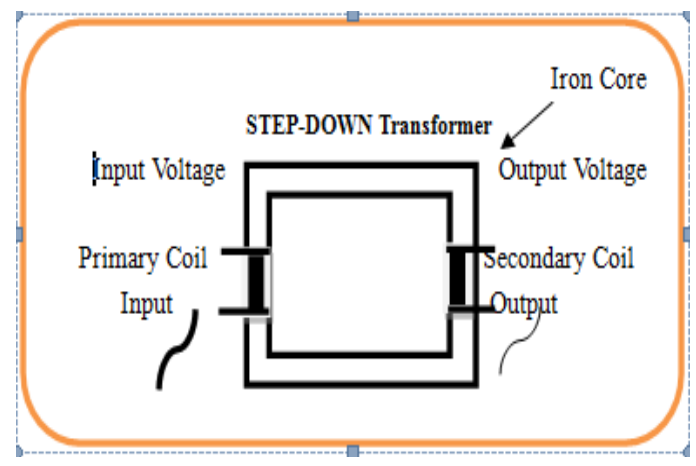

Fig. 5 Step Down Transformer

3.3.1. WORKING OF STEP DOWN TRANSFORMER: A transformer of the step down subsisted with the reservoir of power; the voltage is abdicated to $12 \mathrm{~V}$ AC by this transformer. This AC is converted to DC by employing the bridge rectifier, by manipulating a voltage regulator it is delimited to $5 \mathrm{v}$, for the campaign of the 
microcontroller which is also utilized. The valve peels and water hastens to the harvest through the pipes, when the relay is activated. To assemble the inverter adjourn the prompting of the original timer, the resistance of soil declined and the probe's transmission activates when the water delight in the soil growth. Ultimately the valve is interrupted which is joined with the relay. By virtue of turning into dry to the microcontroller the time ejects the logic signal 0 , this shifts the motor to pump water to the grounds and deactivate the circuit of the motor driver. Conclusively, in the display of LCD shows the soil and state of the motor. The Soil has the large and fubsy resistance and when the soil is arid and wet respectively. Two probes that are placed into the earth consisted of this circuit. When the soil resistance is low and high then the probes could pursue and could not pursue work respectively.

\subsection{VOLTAGE REGULATOR}

To provide a stable DC voltage dent of the load current, temperature, and AC line voltage variations, we use a Voltage regulator is an electronic circuit. A simple feedforward design used by a voltage regulator or negative feedback also included by the same voltage regulator. An electromechanical mechanism or electronic components may be used by it. To regulate one or more AC or DC voltages it may be used, depending on the design. Electronic voltage regulators are found in devices such as computer power supplies within here Electronic voltage regulators are found, DC voltages stabilized by them and processor, other elements use it. By means of a spring-loaded, double-pole switch here in motor vehicles, voltage regulators rapidly switch from one to another of 3 circuit states.

To boost the generator's magnetic field, at low speeds some current from the generator is used to thereby increasing voltage output. Resistance is inserted into the generator-field circuit at higher speeds so that its voltage and current are moderated. The circuit is switched off at still higher speeds, by lowering the magnetic field.

\subsection{CRYSTAL OSCILLATOR}

With an accurate frequency for producing a signal of electric by utilizing the mechanical plangency of a vibrating crystal of piezoelectric substantial, a crystal oscillator used as an electronic oscillator circuit. To maintain time track, this frequency is regularly used, as in quartz wristwatches, for digital integrated circuits by supporting a stable clock signal, and for receivers and transmitters of radios for alleviating frequencies. Quartz crystal is utilized as the frequently general kind of piezoelectric resonator, so by enduring as crystal oscillators, the oscillator circuits integrated, but embracing in identical circuits, polycrystalline ceramics are utilized as well as constituted by another piezoelectric substantial. A quartz crystal provokes a crystal oscillator, trade by being perverted it pursued. When voltage is supplied to an electrode adjacent or on the crystal by an electric field. This resource is called inverse piezoelectricity or electrostriction. When the field is displaced, the quartz - an electric field is created and oscillated in an explicit frequency, as this can produce a voltage by recoils to its earlier outline. Prefer an RLC circuit, a quartz crystal acquits and precipitates result. From some tens of kilohertz to hundreds of megahertz, Quartz crystals are produced for frequencies.

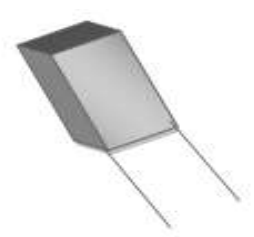

Fig. 6 Quartz Crystal Oscillator 


\subsection{LCD-}

A flush-board panorama such as a liquid crystal display (LCD) or another optical device which is harmonized electronically rapidly in which light-amending resources of liquid crystals is employed.

Light could not be emanated straightly over liquid crystals, rather than for provoking snaps in color or monochrome by employing a reflector or backlight. With fubsy statistics serene for demonstrate erratic images (as in a common-objective computer display) or regulate images LCDs are available, such as 7-segment displays, digits, present words as in a digital clock which could be demonstrated or abstruse. Alike pivotal technology utilized by them, besides that a huge number of few pixels generates the erratic snaps, whilst superior component having with another display. Applications encompassing aircraft cockpit displays, and outdoor and indoor signage, LCD TV, Desktop monitor, device panels, here LCDs are used in a broad range. Instruments such as mobile telephones, calculators, watches, digital cameras incorporating smartphones in which LCD screens (small sized) are ordinary in compact end-user. On clientele electronics artifact like as clocks, DVD players and video game devices; here screens of LCD are also employed. Currently in all appropriateness the bulky, heavy CRT (Cathode Ray Tube) displays has been superseded by LCD Screens, with the same LCD screens which are accessible in extents spanning from puny digital watches to enormous, huge-screen tv sets, Here LCD screens are acquirable in a larger scope of screen sizes on comparing to displays of plasma and CRT.

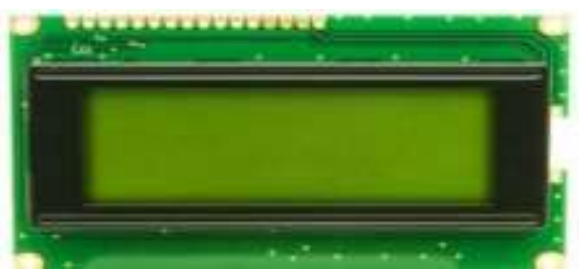

Fig. 7 LCD

\subsection{RELAY}

Circuits are peeled and barred an electronically or electromechanically by the switches of relay by revealing and fastening contacts in another circuit, one electrical circuit is commanded by relays. When the relay is not stimulated there is a peel contact, when a relay contact is generally revealed. When the relay is not invigorated then there is a barred contact when a relay contact is Ordinary fastened (OF). In other case, contacts will evolve their condition when executing the electrical current.

Together with antipode currents, terminate current, beneath current and overcharged; perceiving electrical deviations destruct the device, which is further obviated by a precautionary relay. An electrically regulated switch is a relay. To perform a switch instinctively, here electromagnet is utilized by several relays. Such as solid-state relays, another principle of operation is also used. For authorizing a circuit by a detach signal of low power, it is essential to employed relay or where one signal commands the many circuits. In exchanges of telephone, for executing operations logically it is also being utilized in early days desktop. 


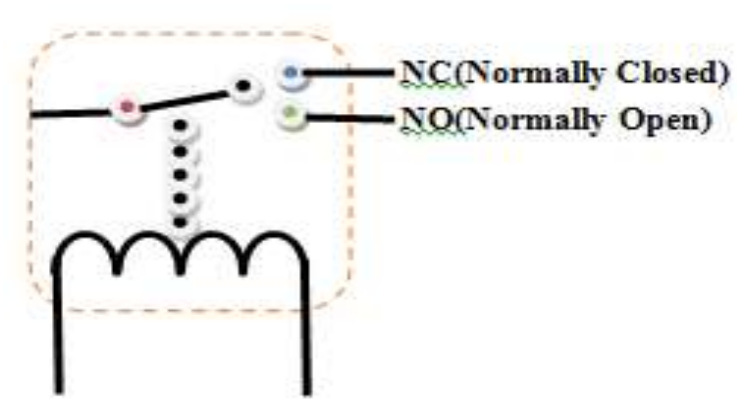

Fig. 8 Relay

\subsection{CAPACITOR}

Energy is not squandered by the capacitor. Potential energy is reserved in a charged field by a capacitor which is a submissive electrical component of two terminals. The capacitance is called as the outcome of a capacitor. For the period that in a circuit of proximity between any two electrical conductors some capacitance is endured. For computing capacitance, to a circuit, a capacitor is a designed intrinsically. Primarily condenser has been entitled as a capacitor. The capacitor's physical form and construction practically alter broadly and in general there are several capacitors to employ.

Frequently with the appearance of metallic outwards or sheets detached by a moderate of dielectric, max capacitors embrace not less than two electrical conductors. An electrolyte, sintered bead of metal, thin film, foil they all may be a conductor. For enhancing the capacitor's charge contents, the dielectric of non-conducting perform. By including oxide layers, mica, paper, plastic film, ceramic and glass as a substantial dielectric are generally utilized. In most ordinary electrical machines as a kind of electrical board, here capacitors are extensively utilized.

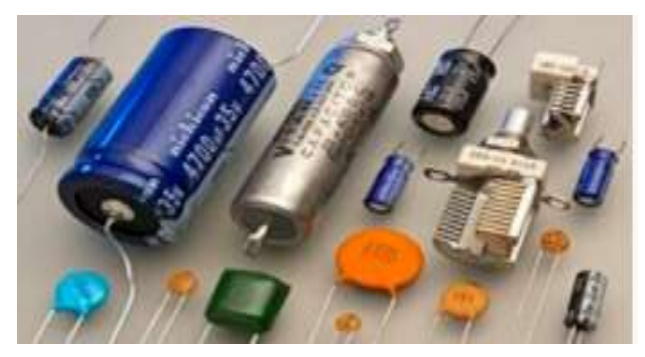

Fig. 9 Capacitor

\subsection{RESISTOR}

For contravening resistance of electrical machine as a circuit element here a resistor is utilized as a submissive two-terminal electrical integrant. For concluding lines of transmission, for mitigating the stream of current, for regulating the levels of signal, for stimulating bias elements, for separating voltages among other users here resistors are utilized in electronic board. As a heat several watts of electrical power is squandered by elevated-power resistors. For generators as a trial load, as a motor controls part, in power dispensation systems; it may be employed, to marginally convert with functional voltage, time, and temperature; here permanent resistors hold resistances. For perception, the activity of chemical, pressure, moistness, beam, warmth or for adapting circuit elements (such as a volume command or a lamp rheostat) unstable resistors can before own. 


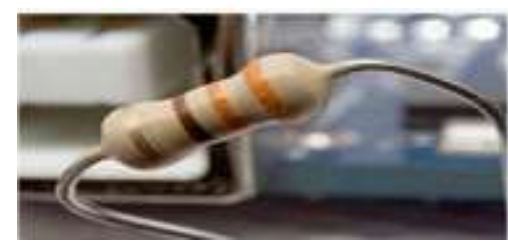

Fig. 10 Resistor

\subsection{MOTOR}

For transforming candid current from electrical to mechanical energy, here A DC motor is a class of revolving electrical instrument is used. Rely on the forces composed by fields of magnetic is the ultimate ordinary type. The various interior mechanism having with almost all kinds of DC machines, repeatedly for transforming the regulation of ongoing stream in the type of the machine either electronic or electromagnetic.

DC motors were the prior kind extensively used, since from prevailing straight- current ignition power dispensation setup they could be energized. Through a broad scope, a DC motor's velocity could be authorized, either converting the fervor of current in its field twisting or by utilizing a fluctuate arsenal of voltage. In tools, instruments, toys, and appliances here tiny DC motors are used. On the straight current the adaptable motor could be maintained, but for the compact power apparatuses and equipment a delicate motor used. In impetus of upraising, conveyor and electric transportation as well as in excursions for steel lurching mills here higher DC motors are pre-owned.

3.11. TRANSISTOR: An electron and hole charge carters both are passed on by a bipolar junction transistor (BJT) is a kind of transistor. Invariance, one type of charge conveyer is utilized by transistors of unipolar, such as field-footprint transistors. For their process, in between two semiconductor types, $\mathrm{N}$ and $\mathrm{P}$ here two junctions are pre-owned by BJT. To be inclined as switches or amplifiers this is enabled by BJT, an electronic apparatus. Necessary to incorporate radio conveyance, commercial control, audio amplifiers, mobile handsets, TV, computers to provide them spacious pertinence.

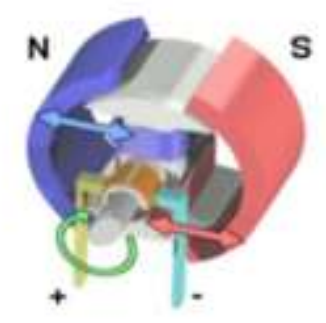

Fig. 11. Transistor

NPN and PNP are two fabricate types of BJT, and as a unique components NPN and PNP are available, or constantly in maximum numbers, in unified circuits, they all are also contrived. For amplifying current is the essential job of BJT. 


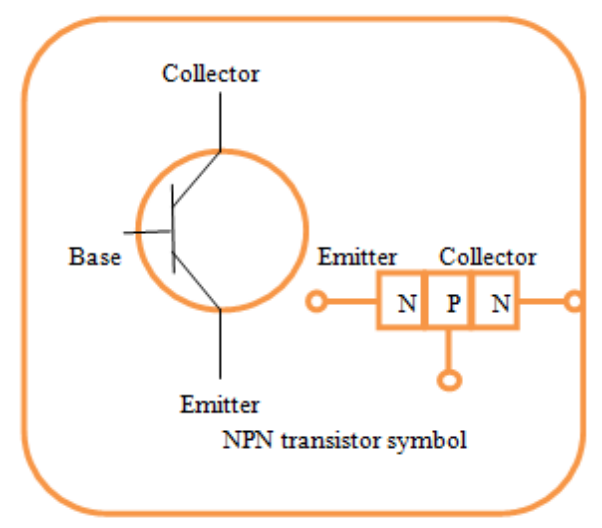

Fig. 12 NPN Transistor

3.12. DIODE: For regulating the current which is especially in one direction with asymmetric conductance; for this, the diode is deployed as a two-terminal electronic integrant. It has less (preferably zero) resistance and large (inherent unbounded) resistance in one and other regulation respectively. At present, the ultimate ordinary type diode is pre-owned a semiconductor diode. Within a $\mathrm{p}-\mathrm{n}$ junction which is joined to two electrical incurables is utilized by a pellucid fragment of semiconductor corporeal. A sheet (anode) and a heated cathode; both are the kinds in electrodes of vacuity tube diode. The earliest semiconductor electronic machine was the semiconductor diodes. Around 1906 the Cat's whisker diodes were avowed as the first semiconductor diodes manufactured, this diode is composed of Galena as mineral crystals. At present scenario, silicon is inclined to created many diodes, but eventually, selenium and germanium are familiarized as another component.

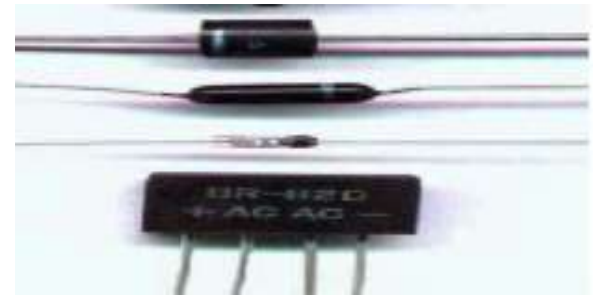

Fig. 13 Diode

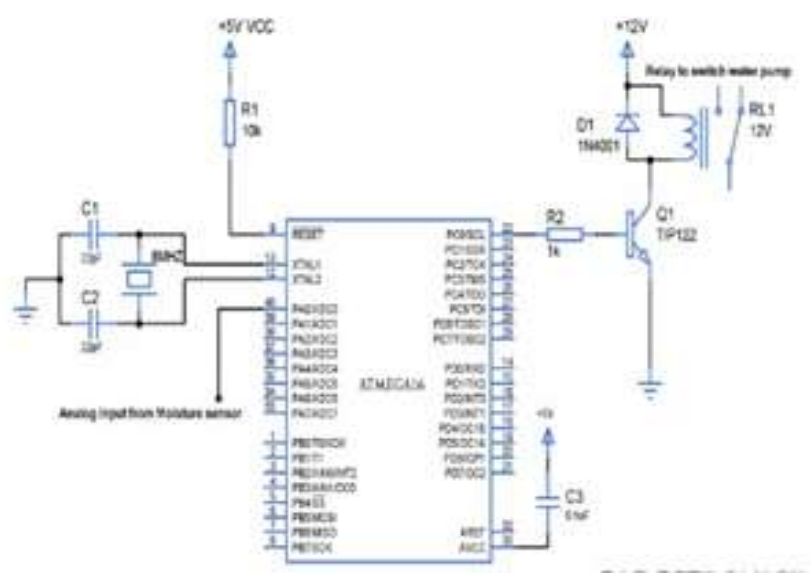

Fig. 14 CKT Diagram of Diode 


\section{PROS OF SMART IRRIGATION SYSTEM}

\subsection{OBVIATES INFECTION AND THREADS}

Relatively scrupling the whole garden like a conventional cloudburst, peculiarly it is finer to candid water to each greenery's root ball. Consequently, the method of incubation could not be drilled by weed surrounded by it, so you would have inferior weeding to do. Leaf disorder affected by perpetual driblets on the leakage is prevented by water at the roots. Because the leaves or flowers are not thwacked by the water, there is no cause of accumulating with blemish diseases.

\subsection{A COUNTER POLE OF TIME AND WATER}

Considerable time could be consumed by hand watering with a drenching or damp, observance of fresh morning and evening dampening carry away from family members and their work. So you don't require monitoring the drenching since the timer cages the water off when it has completed, as timers have with both dribble and sprayer inundation systems could stipulate for every week and day-to-day watering. If the sprinkling system is productive, your water invoice must be inferior.

\subsection{MAINTAINS SOIL FABRIC AND SUPPLEMENTS}

For exuding into the soil, sprinkling with a broadly usable garden, a hose may enable max amount of water. Subsequently by fleeing the greenery with scarcer minerals, with the drainage of water so the minerals will percolate out. With a hose when you water, the soil may also be condensed. With constricted soil, stifling; greenery may unveil traces of root disorder or devastating. To conduct inferior dewdrops, deploy either dribble or drenching irrigation, which nourish for condensing constricts of soil and conserve supplements.

\subsection{GARDENING FLEXIBILITY}

You would embrace being capable to perform in the lawn concurring as the greenery are being drenched if you have a tireless routine. You can verdure and Pollard in another area, while one-yard territory is being soaked.

\section{CONCLUSION}

With numerous fields of application \& various advantage of the system has made it one of the major option available for the farmers. The increasing interest in this area of research may bring about more and more consumer efficient system. Later scarcity the major problem is well handled by the system. The changing climatic condition and global warming issues prevailing throughout the world can be overcome only through this system. The automatic irrigation system will be every farmer's choice in a decade or so. The improper advertising was the sole reason for the late adoption and acquaintance of the system that took place in the late eighties. But with the awareness spreading all over the globe the system is earning acceptance and so, a number of scientists are investing their time to perfect the system we can implement this module in golf fields and public gardens. Electronic Gardner is a prototype for an automatic irrigation system that can be used in wide landscapes. The main advantage of this module is without observation of farmer the motor pump automatically switches the motor on or by using the moisture sensors. In the self-regulating sprinkling system, by preserving water and time, thousands of gauges of water could be reserved per year commonly at the fair time by thinking of to turn it off. 


\section{REFERENCES}

[1] Rafael Munoz Carpena and Michael D. Dukes, Automatic Irrigation Based on Soil Moisture for Vegetable Crops, IFAS extension - 2005.

[2] Yiming Zhou, Xianglong Yang, Liren Wang, Yibin Ying, A wireless design of low-cost irrigation system using ZigBee technology, International Conference on Networks Security, Wireless Communications and Trusted Computing, IEEE 2009.

[3] Sankar, P., Norman, S.R,(2009) "Embedded System for Monitoring Atmosphere is Weather Conditions Using Weather Balloon", International Conference on Control, Automation, Communication and Energy Conservation 2009, pp 1-4.

[4] Md. Wasi-ur-Rahman, Mohammad Tanvir Rahman, TareqHasan Khan and S.M. LutfulKabir,(2009)“Design of an Intelligent SMS based Remote Metering System”,Proceedings of the IEEE International Conference on Information and Automation pp. 1040-1043

[5] Mahesh M.Galgalikar,(2010)"Real-Time Automization Of Agricultural Environment for Social Modernization of Indian Agricultural System", on IEEE Proceedings,pp 20- 23.

[6] Vasif Ahmed, Siddharth A. Ladhake,(2010) "Design of Ultra Low Cost Cell Phone Based Embedded System for Irrigation", on International Conference on Machine Vision and Human Machine Interface, vol.20,pp 40-45.

[7] P. Corke, T. Wark, R. Jurdak, H. Wen, P.Valencia, D. Moore, "Environmental wireless sensor networks," "Proc. IEEE", vol. 98, no. 11, 2010.

[8] Bircher, S., Skou, N., Jensen, K.H., Walker, J.P., \& Rasmussen, L. (2011). A soil moisture and temperature network forSMOS validation in Western Denmark. Hydrol. Earth Syst. Sci. Discuss., 8, 9961-10006.

[9] L .L.Pfitscher, (2011) "An automated irrigation system for rise cropping with remote supervision"proceeding of international conference on power engineering, energy and electrical devices, vol. 50, pp 90.

[10] Y. Kim, J. D. Jabro, R. G. Evans, "Wireless lysimeters for real time online soil water monitoring," IEEE Transactions On Irrigation Science”.” Irrigation Sci.”, vol. 29, no. 5, 2011.

[11] Abhinav Rajpal, Sumit Jain, Nistha Khare and Anil Kumar Shukla, "Microcontroller based Automatic Irrigation System with Moisture Sensors", Proceedings of the International Conference on Science and Engineering, 2011, pp. 94-96

[12] Zhang Feng, "Research on water-saving irrigation automatic control system based on Internet of things",978-1-4244-8039-5/11/\$26.00,2011 IEEE

[13] Venkata Naga RohitGunturi, "MicroController Based Automatic Plant Irrigation System”, International Journal of Advancements in Research \& Technology, Volume 2, Issue4, April-2013

[14] Veena Divyak ,Ayush Akhouri,A Real time implementation of a GSM based Automated Irrigation Control System using drip Irrigation Methology (Volume 4, Issue 5,May 2013).

[15] Joaquin Gutierrez ; Juan Francisco VillaMedina ; Alejandra Nieto-Garibay ; Miguel Angel Porta Gandara , "Automated Irrigation System Using a Wireless Sensor Network and GPRS Module " IEEE Transactions 19 August 2013

[16] Mansour ,H.A, You sifEl-Melhem ,impact the automatic control of closed circuits raingun irrigation system on yellow corn growth and yield(International Journal of Advanced Research (2013), Volume 1, Issue 10, 33-42)

[17] Chandraprakash Patidar, "E-IRRIGATION: An Automation of Irrigation using Wireless Networks", International Journal of Scientific Research in Network Security and Communication, Vol.1, Issue.5, pp.18-20, 2013.

[18] Joaquín Gutiérrez, Juan Francisco Villa-Medina, Alejandra NietoGaribay, and Miguel Ángel PortaGándara" Automated Irrigation System Using a Wireless Sensor Network and GPRS module", Ieee Transactions OnInstrumentation And Measurement, Vol. 63, No. 1, January 2014.

[19] R.Suresh, S.Gopinath, K.Govinda raju, T.Devika, N.Suthanthira Vanitha, "GSM based Automated Irrigation Control using Rain gun Irrigation System", International Journal of Advanced Research in Computer and Communication Engineering Vol. 3, Issue 2, February 2014.

[20] Shiraz Pasha B.R., Dr. B Yogesha, - Microcontroller Based Automated Irrigation Systemll, The International Journal Of Engineering And Science (IJES), Volume3, Issue 7, pp 06-09, June2014.

[21] S. V. Devika, Sk. Khamuruddeen, Sk. Khamurunnisa, Jayanth Thota, Khalesha Shaik, "Arduino Based Automatic Plant Watering System", Devika et al., International Journal of Advanced Research in Computer Science and Software Engineering 4(10), October -2014, pp. 449-456 Volume 4, Issue 10, October 2014

[22] Deweshvree Rane, P.R. Indurkar, D.M. Khatri, "Review Paper Based On Automatic Irrigation System Based On RF Module", IJAICT Volume 1, Issue 9, January 2015

[23] Nikhil Agrawal, Siemens Noida, Smita Singhal, "Smart Drip Irrigation System Using Raspberry Pi and Arduino",978-1-4799-8889-1, May 2015, IEEE.

[24] S. Darshna, T.Sangavi , Sheena Mohan, A.Soundharya, Sukanya Desikan , "Smart Irrigation System", IOSR Journal of Electronics and Communication Engineering Volume 10, Issue 3, Ver. II (May Jun.2015). 
[25] Karan Kansara, Vishal Zaveri, Shreyans Shah, Sandip Delwadkar, Kaushal Jani, "Sensor based Automated Irrigation System with IOT: A Technical Review", Karan Kansara et al, / (IJCSIT) International Journal of Computer Science and Information Technologies, Vol. 6 (6), 2015, 5331-5333

[26] Stefanos A. Nikolidakis, Dionisis Kandris,Dimitrios D. Vergadoschristos Douligeris A"Energy Efficient Automated Control Of Irrigation In Agriculture By Using Wireless Sensor Networks, Computers And Electronics In Agriculture "0168-1699/2015 Elsevier B.V

[27] Archana P, Priya R, "DESIGN AND IMPLEMENTATION OF AUTOMATIC PLANT WATERING SYSTEM", International Journal of Advanced Engineering and Global Technology Vol-04, Issue-01 January 2016, ISSN No: 2309-4893

[28] Rekha Sharma, Heena Das, S.N. Das, "WSN for Computerized Irrigation System in Tea Gardens", International Journal of Scientific Research in Computer Science and Engineering, Vol.4, Issue.2, pp.2630, 2016.

[29] Shiny Rajendrakumar, Dr. Rajashekarappa, V. K Parvati, Dr. Parameshachari B D, Dr. Reshma Banu, "An Intelligent Report Generator for Efficient Farming", presented in International Conference on Electrical, Electronics, Communication, Computer, and Optimization Techniques (ICEECCOT) IEEE, on 15th \& 16th December 2017, Mysore. (Best Paper Award and IEEE Scopus Indexed), pp 948--952, 978-1-5386-2361-9/17/\$31.00 @ 2017 IEEE.

[30] Srishti Rawal," IOT based Smart Irrigation System", International Journal of Computer Applications, Volume 159 - No, 2017

[31] Shiny Rajendrakumar, V K Parvati, Dr. Rajshekarappa, "An Efficient Irrigation System for Agriculture", presented in International Conference on Communication, Computing, and Internet of Things (IC3IoT 2018) IEEE, on 15th to 17th February 2018, Chennai. (IEEE), pp 151--155, 978-1-5386-2459-3\$31.00 (C) 2018 IEEE.

[32] M.N. Gogoi, "An automated garden irrigation system: Controlled and monitored via Arduino and LabVIEW", International Journal of Computer Sciences and Engineering, Vol.6, Issue.5, pp.1172-1176, 2018. 